\title{
Mechanical Properties of Chalk with Emphasis on Chalk-Fluid Interactions and Micromechanical Aspects
}

\author{
R. Risnes ${ }^{1}$ and O. Flaageng ${ }^{1}$ \\ 1 Stavanger College, PO Box 2557 Ullandhaug, N-4091 Stavanger - Norway \\ e-mail: rasmus.risnes@tn.his.no
}

\begin{abstract}
Résumé - Propriétés mécaniques de la craie : interactions fluide-craie et aspects micromécaniques — Le présent article traite du problème des effets affaiblissants de l'eau dans la craie. L'utilisation des fluides miscibles permet l'élimination des forces capillaires. Des expériences réalisées avec de l'eau et du méthanol ont démontré que la craie saturée au méthanol est considérablement plus résistante que la craie saturée à l'eau. Une étude sur les mélanges eau-méthanol a indiqué que la transition est progressive, dépendant uniquement de la composition du fluide.

Les changements des propriétés mécaniques peuvent être expliqués par des forces répulsives au contact des grains. La forte interaction entre les molécules d'eau fortement polarisées et la surface de la craie peut donner lieu à des couches chargées ou polarisées, qui développeront des forces répulsives en présence de deux surfaces en contact proche, comme dans la zone de contact de grain.

Mots-clés : craie à forte porosité, propriétés mécaniques, saturation en fluides, mélanges eau/méthanol, effet affaiblissant de l'eau, mécanismes au contact de grains.
\end{abstract}

\begin{abstract}
Mechanical Properties of Chalk with Emphasis on Chalk-Fluid Interactions and Micromechanical Aspects - The paper addresses the problem of water weakening effects in chalk. Using miscible fluids, capillary forces can be eliminated. Experience with water and methanol has revealed that methanol saturated chalk is considerably stronger than water saturated chalk. A study of water-methanol mixtures has shown that the transition is a gradual one, only dependent on the composition of the fluid. The changes in mechanical properties can be accounted for by repulsive forces at the grain contacts. The strong interaction between the highly polar water molecules and the chalk surface may give rise to charged or polarized layers which will develop repulsive forces when two surfaces are in close contact, like in the grain contact region.

Keywords: high porosity chalk, mechanical properties, saturation fluids, water/methanol mixtures, water weakening effect, grain contact processes.
\end{abstract}

\section{INTRODUCTION}

Mechanical properties of chalk have received considerable attention during the last decades. Several of the North Sea chalk reservoirs have experienced well instability problems, compaction and subsidence. The most important examples are the Ekofisk field (Phillips) and the Valhall field (Amoco).
Pure chalks are mainly built up of whole and fragmentary skeletons produced by planktonic algae known as coccolithophorids. The building blocks of the skeletons are calcite tablets or platelets of typical dimension $1 \mu \mathrm{m}$. These calcite grains are arranged in rings or rosettes known as coccoliths, typically $10 \mu \mathrm{m}$ in diameter. Pure high porosity chalks consist of a mixture of intact coccolith rings and greater and 
smaller fragments. This gives the chalk material a rather open structure, where the dimensions of the pore space may be considerably greater than the dimensions of the individual grains. On the other hand, the smallness of the grains make the pore throats rather narrow, and the permeability of even high porosity chalks is typically only a few $\mathrm{mD}$. A typical scanning electron microscope (SEM) picture of high porosity chalks is presented in Figure 1. The chalk is an outcrop chalk from Liège, Belgium, and the chalk surface was prepared by splitting in a Brazilian test.

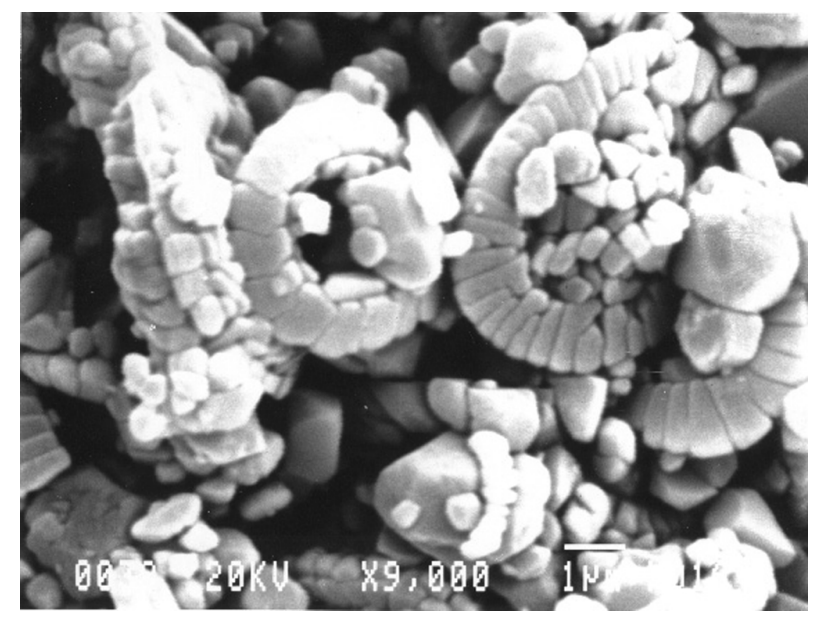

Figure 1

SEM photo of chalk from Liège (Belgium)

In scanning electron microscope pictures cement bonds between the grains are rarely if ever seen. But that does not mean that cement bonds are absent. Sometimes recrystallized calcite grains have been observed [1], indicating that some degree of calcite cementation might have taken place, but also silica could be a cementing agent. In addition the calcite skeleton fragments may have an organic coating [2], which might also be an important element in the bonding of the chalks.

The weakness of the high porosity chalks makes them strongly susceptible to compaction when subjected to burial in the ground. However, the presence of overpressured hydrocarbons at an early stage have prevented many reservoir chalks from being naturally consolidated, and they have to a great extent preserved their initial high porosity (Ekofisk, Valhall).

\section{SOME GENERAL PROPERTIES OF CHALK}

Mechanically, high porosity chalks behave as frictional materials, failing in a shear failure mode. However, the open structure of these chalks enhances another failure mechanism, often referred to as pore collapse. Chalk grains may relatively easily be forced into the pore space, resulting in a kind of internal implosion. This type of failure may take place even under hydrostatic loading when no macroscopic shear stresses are present. But shear stresses at a microscopic level may well develop and start this type of deformation [3].

With these two types of failure modes chalks may mechanically be described by a Mohr-Coulomb type failure criterion with an end cap like illustrated in Figure 2.

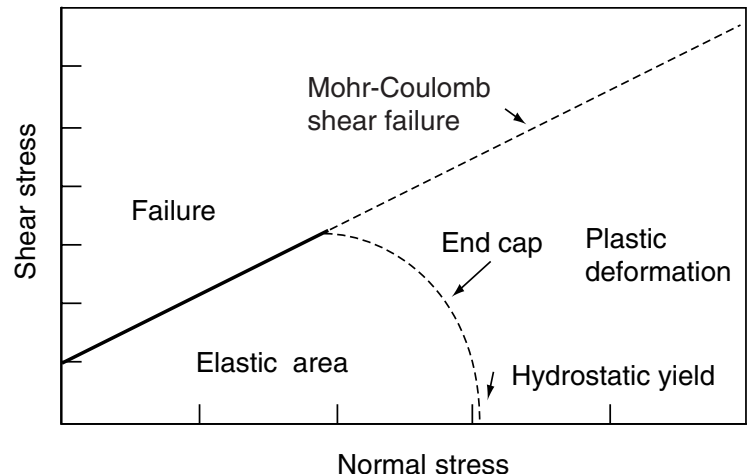

Figure 2

Typical yield or failure diagram for chalks.

In addition, creep effects are important in high porosity chalks. Experimental studies have revealed that strain during creep is proportional to the logarithm of time [4]. Also in the elastic domain creep effects may be seen, making the term elastic partly misleading. The elastic region should probably better be referred to as the region of linear (instantaneous) response.

Extensive experimental studies on chalk behavior have revealed that the main parameters affecting the mechanical properties are porosity and silica content [5]. Weak chalks are characterized by high porosity $(35-45 \%)$ and low silica content $(<5 \%)$. However, even though pure high porosity chalks have great similarities, they are not equal. In evaluating experimental results it is therefore not always easy to distinguish between general and more field specific properties, and the influence of experimental conditions has to be carefully considered. A problem of great practical importance is the effect of water on reservoir chalks. Much work has been done on this subject, but still the basic mechanism behind the chalk-water interaction is not completely understood.

In an early phase of the research activity that started after the Ekofisk subsidence was detected, it was observed that water has a pronounced weakening effect on chalks [6]. Oil saturated samples turned out to be 2-3 times as strong as water saturated samples, like illustrated in Figure 3. 


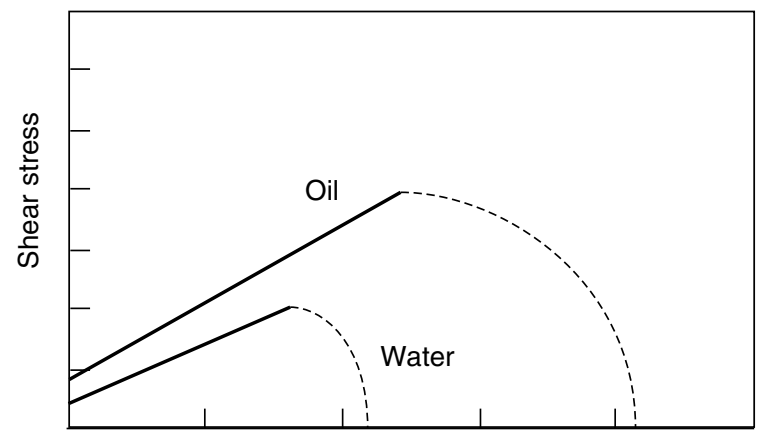

Normal stress

Figure 3

Comparison between oil and water saturated chalk.

Typically the hydrostatic yield value for water saturated chalk could be $10 \mathrm{MPa}$, while for oil saturated samples it could increase to 20-30 MPa. Even though this phenomenon has been known for many years, it is still a puzzling question that has not yet been fully explained.

Mechanical properties are determined both in compressional and extensional tests. The most important parameters are:

- $S_{o}$, cohesion, the shear strength with zero normal stress on the shear plane;

$-\varphi$, friction angle, parameter that reflects the increased shear strength due to normal stress $\sigma, \tau_{\max }=S_{o}+\mu \sigma$ where $\mu=\tan \varphi$;

$-\sigma_{o}$, hydrostatic yield value, marks the onset of pore collapse;

$-T_{o}$, tensional strength;

$-E$, Young's modulus, elastic parameter;

- Poisson's ratio, elastic parameter.

The definitions of the strength parameters are given in Figure 4.

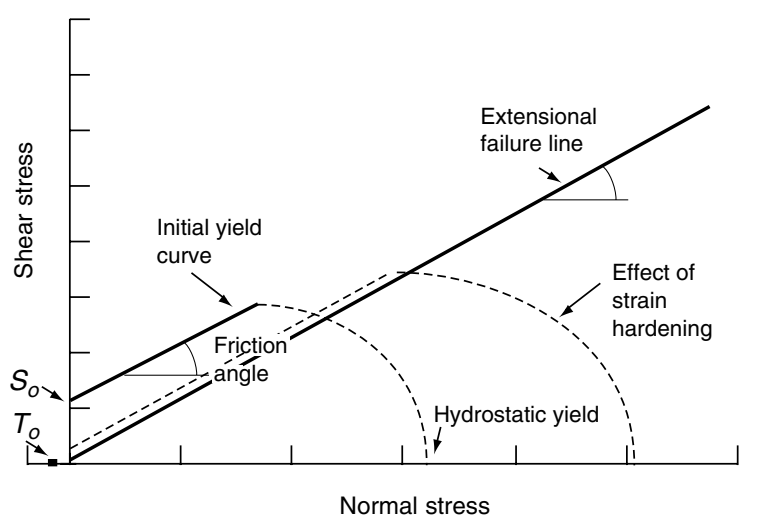

Figure 4

Definition of strength parameters.
Some general observations are added to the figure. If the material is deformed hydrostatically beyond the elastic limit, it will apparently enter into a strain hardening process. But in this process most of the cohesion is lost, and the resulting yield curve will look like the dashed one in Figure 4. However, some apparent cohesion may be regained at high loading stresses, probably due to a sintering effect [7]. Also the tensile strength is greatly reduced when the material is deformed beyond the elastic limit [8].

In extension tests where the confining pressure is kept constant and the axial stress reduced, the plugs will finally fail by deforming under constant forces. In tests starting outside the elastic range, the failure points fall around a straight line with the same slope as the compressional failure line for water, but with no cohesion. This behavior in extension seems rather general [7]. Different fluids make no difference, while the strength parameters in compression may be strongly dependent on the fluid type [9]. However, extension tests within the elastic range seem to approach the compressional failure line corresponding to the actual pore fluid.

Up till now the fluids most extensively studied are water and methanol. Based on series of tests the following values are reasonably representative:

TABLE 1

\begin{tabular}{l|c|c}
\hline & Water & Methanol \\
\hline So (MPa) & 0.9 & 1.3 \\
j (degrees) & 30 & 40 \\
so (MPa) & 10 & 15 \\
To (MPa) & 0.8 & 1.2 \\
\hline
\end{tabular}

It is obvious from the table above that methanol saturated chalk is considerably stronger than water saturated chalk.

The water used for saturation has normally been equilibrium water. However, this does not seem critical. Samples saturated with synthetic seawater show only a small weakening tendency, if any at all [10]. Another observation is that the water weakening effect to some extent is a reversible effect. When water in a water saturated sample is replaced by methanol, the sample becomes stronger against compression [11].

The results presented above were all obtained with outcrop chalk, which is preferentially water wet. A few tests have been performed with a reservoir chalk that was neutral to oil wet. In that case flooding oil saturated samples with water showed a strengthening effect [10]. This indicates that wettability is an important parameter in chalk-fluid interactions.

\section{CAPILLARY THEORY OF CHALK-WATER INTERACTION}

An attempt to resolve the problem of chalk-water interaction as a mechanism due to capillary forces, has been put forward during the recent years [9]. Because of the fineness of the 
chalk grains capillary pressures and capillary forces may be several orders of magnitude greater than normally experienced in sand. Estimates have been presented that indicate that under normal drying conditions the water bridges cannot be completely removed, and the situation will be like indicated in Figure 5. If now the chalk is saturated with oil or tested in dry conditions, these water bridges will provide an important contribution to strength. If however the chalk is saturated with water, these capillary forces will disappear and the chalk will become substantially weaker as observed.

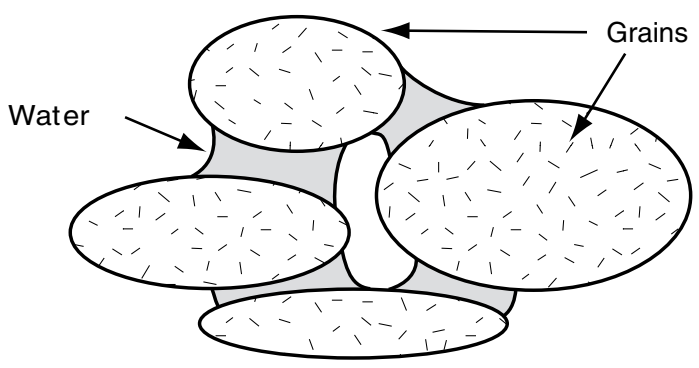

Figure 5

Chalk grains hold together by capillary forces.

However, the capillary forces may be eliminated by other fluids than water. Methanol is miscible with water in all proportions, and if a sample is saturated with methanol, there will likewise be no capillary forces. Yet, methanol saturated chalk is considerably stronger than water saturated chalk. The yield curve will typically fall in between the curves sketched in Figure 3. This shows that capillary forces cannot be the only mechanism in explaining water weakening. The strength of the chalk depends also on the type of fluids present in the pores.

\section{A STUDY OF WATER-METHANOL MIXTURES}

In order to achieve a better understanding of the chalk-fluid interactions, a test program was designed to study the effect of different water-methanol mixtures on the failure modes in chalk: shear failure, pore collapse and tensional failure.

Liège chalk was used in this study. Typical properties for this chalk are:

- age: upper Campanian;

- average porosity: $40 \%$;

- silica content: less than $2 \%$;

- permeability: $1-2 \mathrm{mD}$.

These properties classify the chalk as a high porosity and low strength chalk.

The samples were drilled from five different chalk blocks using an oversized bit. To obtain the right diameter of
$37 \mathrm{~mm}$, the samples were machined on a lathe. The samples were then cut to lengths of 70-72 $\mathrm{mm}$ for compressional tests, and 30-37 mm for the Brazilian tests. After drying, the samples were saturated with the different saturation fluids under $5 \mathrm{~Pa}$ absolute pressure. The water-methanol mixtures were prepared on a mole basis, where the percentage of methanol ranged from zero to hundred, through 25,50 and $75 \%$. The water used was equilibrium water. Mole percentage was chosen instead of volume percentage because it would give a better indication if any chemical reactions were present.

Three different test procedures were used in this study:

- standard triaxial compression tests with $1 \mathrm{MPa}$ confining pressure;

- constant stress ratio tests with $K=0.9$ up to $20 \mathrm{MPa}$ confining pressure;

- Brazilian tests to determine tensional strength.

In test procedure 1 , the low confining pressure of $1 \mathrm{MPa}$ was chosen to be sure that shear failure would be the dominating failure mechanism in the samples. From these tests both yield stress and elastic properties, $E$-modulus and Poisson's ratio, could be obtained. Test procedure 2 was chosen as an alternative to pure hydrostatic tests, due to limitations in the test equipment. (The axial strain could only be measured directly with the axial piston in contact with the sample). In these tests pore collapse would be the dominating failure mechanism, and the yield stress in such tests would be close to the hydrostatic yield values. Finally Brazilian tests were chosen as the most convenient way to determine tensile failure.

During the first period of the study we did not take precautions against variation in mechanical properties from block to block. The samples from the first three blocks, labeled A-C, were therefore unevenly distributed with regard to methanol content of the saturation fluid. Upon examining the results, we became aware of the relatively large differences in strength between the samples from different blocks. Because of this we decided to add a D-block with a sufficient number of samples to have at least one sample saturated with each of the saturation fluids for each of the test types. Finally samples from a fifth block, The E-block, were added to fill in some results at higher methanol concentrations (65 and 90\%).

The D-series provide the most complete set of results. In the presentation in the following diagrams, the points from the D-series are emphasized by being connected by a fully drawn curve. The trend lines presented are also based solely on the D-series results. The C-series mostly failed in an irregular way, indicating that different sets of failure planes were activated. These results should therefore be regarded as nontypical.

The yield values in compression tests are presented in Figure 6. There is clearly an increasing trend from water to 


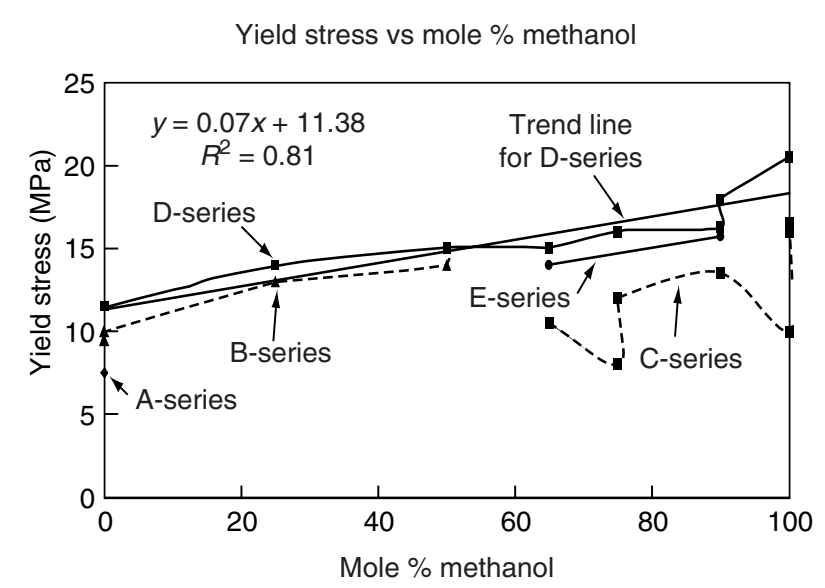

Figure 6

Yield points from compression tests.
E-modulus vs mole \% methanol

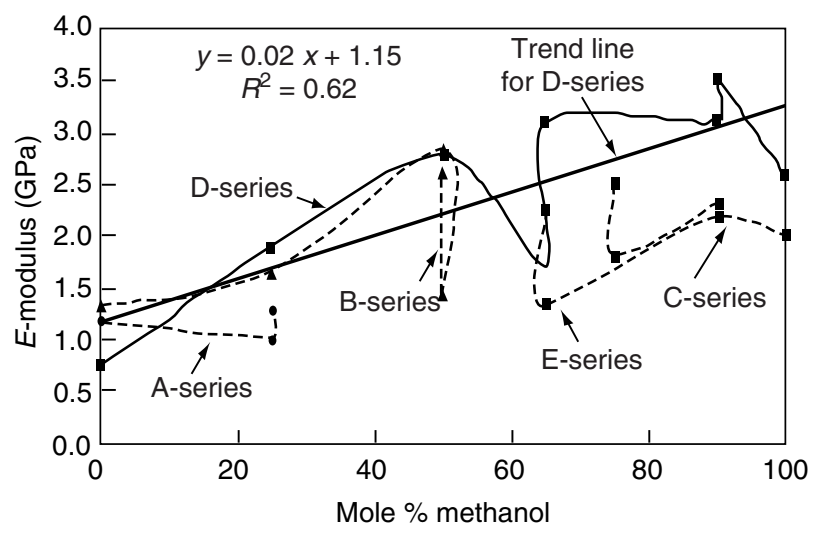

Figure 7

$E$-moduli from compression tests. methanol. Based on the trend line, the yield stress increases from 11 to $18 \mathrm{MPa}$, corresponding to a $50 \%$ increase.

The $E$-modulus values presented in Figure 7, show essentially the same picture. The $E$-modulus increases from around 1 to $3 \mathrm{MPa}$. The values obtained for Poisson's ratio did however not show a clear trend. The spread in the results was too great. But most of the results were within the range of 0.2 to 0.4 .

The yield stresses in the almost hydrostatic tests $(K=0.9)$ are presented in Figure 8 . The results show a very clear trend with only a small spread, except for the C-series.

The yield value increases from around 8 to $12 \mathrm{MPa}$, an increase of more than $50 \%$. The small spread in the results may indicate that the hydrostatic yield value is mainly determined by the average porosity, and to a lesser extent sensitive to local variations in structure and bonding. The deformation moduli in these tests also showed a rather small variation, but uncorrelated to the fluid variation.

The results from the Brazilian tests are presented in Figure 9. The D-series show an increase in tensile strength from 0.6 to $1.0 \mathrm{MPa}$, again an increase of more than $50 \%$. The results from the other series seem to indicate an even stronger variation.

The conclusion based on these series of tests, seems to be that the transition from water to methanol affects the different failure modes in a similar manner. There is an overall

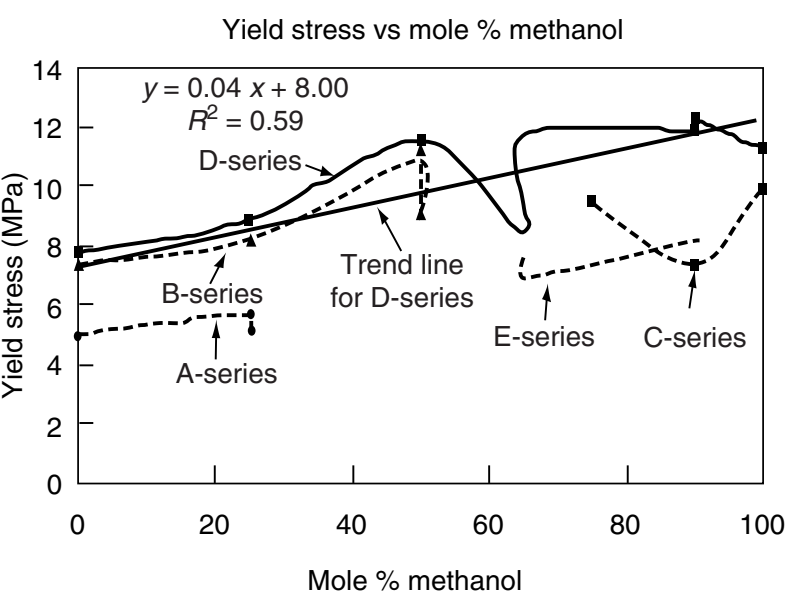

Figure 8

Yield points from tests with $K=0.9$.
Tensile strength from Brazilian tests

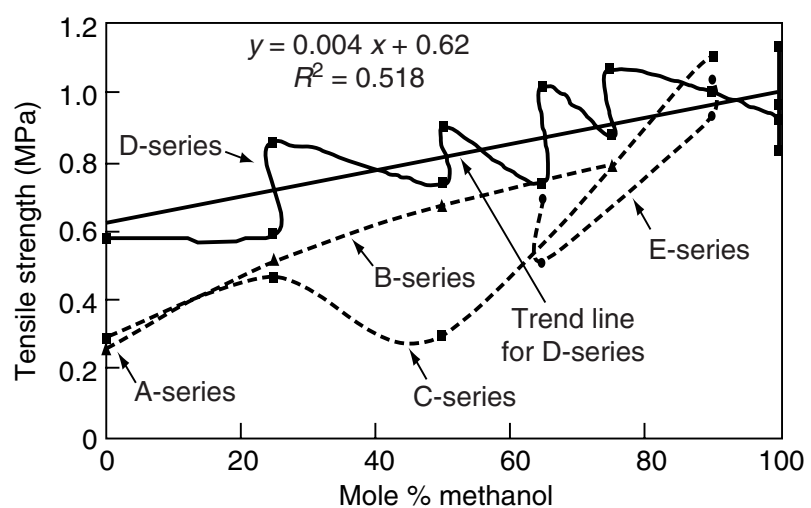

Figure 9

Tensile strengths from Brazilian tests. 
strengthening in going from water to methanol. The transition is clearly a gradual one, but not necessarily linear.

\section{CHALK-FLUID INTERACTIONS ON A MICROSCOPIC LEVEL}

The ideal reference state for discussing effects of different fluids would have been the properties of the chalk skeleton under vacuum, i.e. without any fluids present at all. However, the arguments behind the capillary theory show that such data may be difficult to obtain. An alternative would be to perform experiments with a fluid that is completely inert with respect to the chalk grain surfaces. But such a fluid is not known, at least not yet.

There is some degree of bonding or cementation in the chalk skeleton, irrespectively of the fluids present. This almost obvious statement follows from the fact that chalk deformed beyond the elastic limit, disintegrates under water imbibition, whereas undeformed chalk remains intact [8]. This shows that bonds must have been broken under the deformation process.

The mechanical parameter that most directly reflects the degree of bonding, is probably the tensile strength. In such tests the bonds are simply split apart, and frictional forces can be expected to be small. It has been shown [8], that the tensile strength decreases with increasing degree of plastic deformation, in agreement with the statement in the preceding paragraph. Bonds are progressively broken during the deformation. Although the tensile strength is mostly measured indirectly in the Brazilian test, the results are consistent with the results from direct tensile tests.

When the tensile strengths for water and methanol saturated chalk are compared, the methanol saturated chalk is considerably stronger than water saturated chalk. As there is no capillary forces involved, this difference must be due to interactions between water and chalk. The experiments with water-methanol mixtures also show that this difference evolves gradually, depending on the concentration of water molecules in the mixture.

In tensile tests there is no pressure effect involved, as the pore pressure is kept equal to the atmospheric pressure. The effect of water must therefore be found in the grain contact areas. In search for the basic mechanisms, there are at least two mechanisms that could be considered:

- water softening of the bonds between the grains;

- water induced repulsive forces between the grains.

Pressure dissolution of chalk can be ruled out as an actual process in tensile tests, where the chalk is only saturated and then pulled apart. But this does not mean that such processes may not be active under compressive conditions, and even more so under reservoir conditions on a longer time scale.
A possible picture of a grain contact area is sketched in Figure 10. The asperities on the grain surfaces will probably prevent continuous contact. Some of the contact points may be cemented, forming permanent bonds. But on a microscale the contact area will be open so that a saturating fluid may penetrate. Such a model would be rather similar to the model developed by Murphy et al. [13] for sandstones.

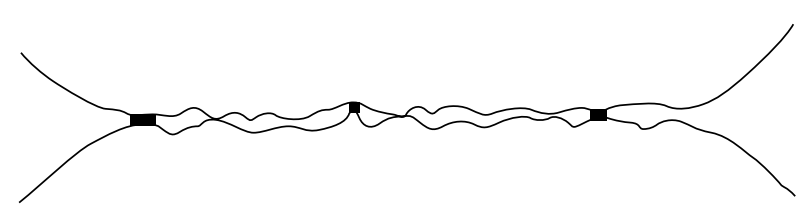

Figure 10

Sketch of a grain contact area. The black dots represent asperity contacts that have been cemented.

We may first consider the possible mechanisms for bond softening. It is difficult to imagine a direct chemical attack on the cement bonds by equilibrium water. And moreover, there is no permanent damage by mere water saturation. When the chalk is dried, the full strength is restored. However, a stress corrosion effect of water on silica bonds observed in sandstones [14], may be effective also in chalks. Subjected to stresses, the strong $\mathrm{Si}-\mathrm{O}-\mathrm{Si}$ bonds will weaken as being stretched, and water molecules may interact and replace the bonds by the weaker Si-OH-OH-Si bonds. A crack may start as the OH-OH bond breaks, but the development of a crack will not be instantaneous as it depends on diffusion of water molecules to the crack tip. The time dependency makes it less probable that this could be the main mechanism behind the water weakening of chalk, especially not in tensile tests, where the test is completed within a few minutes.

The second mechanism to consider is fluid induced repulsive forces at the grain contacts. The outcrop chalks, and also most of the reservoir chalks, are strongly water wet, and will imbibe water spontaneously. This strong adherence of water to the chalk surfaces reflects microelectric processes between water and chalk. Calcite surfaces can acquire a net surface charge by association of ions in the fluid, and thereby creating an electric double layer.

This double layer may create repulsive forces of electrostatic origin when two grain surfaces are very close like in the grain contact area.

A more recent study measuring the zeta potential of chalk powder in different fluids has confirmed that there is a strong interaction of electrostatic nature between the chalk and the fluids. Actual zeta potential values are:

- equilibrium water: $-20 \mathrm{mV}$;

- methanol: $+10 \mathrm{mV}$;

- oil: $\approx 0 \mathrm{mV}$. 
Based on the arguments above, a possible model for the chalk-water interaction would contain two main elements:

- repulsion forces of electrostatic origin generated by the fluid film in the contact area between the grains;

- attractive forces due to the capillary effects when the chalk is not fully saturated with the wetting fluid.

This model is illustrated in Figure 11. Such a model is of course not limited to only chalk and water, but may apply to any chalk-fluid pair where the fluid is adsorbed to the surface. But the magnitude of the forces will depend strongly on molecular properties of the fluid. Also methanol interacts with the chalk surfaces, and spontaneous imbibition will occur in dry chalk. But the experimental values for mechanical properties indicate that the chalk-methanol interaction is rather weak.

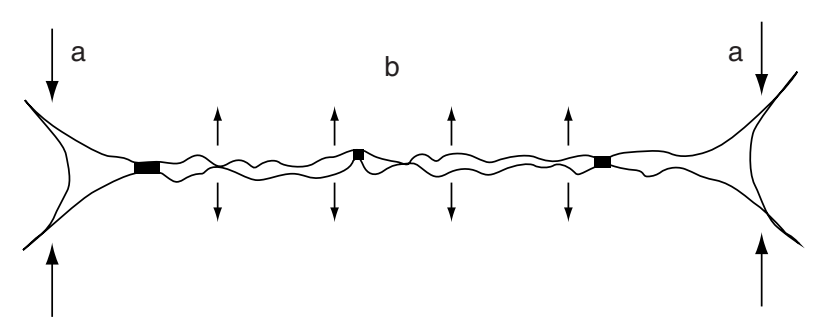

Figure 11

Forces between the grains. a: attractive forces due to capillary effects; b: repulsive forces of electrostatic origin.

The proposed model may readily explain variations in tensile strength caused by the fluids. Repulsive forces will reduce the forces needed to pull the bonds apart. In compression repulsive forces will reduce the forces transmitted through the bonds, making the bonds more susceptible to fail in shear, and the cohesion will be reduced. Also the load on the frictional contacts will be less, reducing the frictional forces that may develop, which in turn corresponds to a reduced friction angle.

Also the sintering effects observed after compression at high stresses, are consistent with the model. Under high stresses more asperities will be brought in contact. The water film may be squeezed out, resulting in a solid-solid adhesion which will act as an increased cohesion of the material [16]. However, in extension tests such sintering effects, and fluid effects in general, seem to play a minor role. The reason is probably that in extension tests the stress level is steadily decreased, making frictional effects due to fluids less important.

The reduced $E$-modulus with increasing water content can also be related to effects of repulsive forces. Water effects on elastic moduli have been demonstrated on several sedimentary rocks in acoustic experiments [17]. But for chalk the $E$-modulus, as measured in the first loading cycle, is not a true elastic modulus. In a recent study, making loadingunloading cycles within the "elastic" area, the E-moduli increase by a factor of 2 to 4 , showing that there is a considerable degree of nonelastic deformation taking place within the so called elastic range [18]. Such cycling does however not seem to give any hardening effects. The chalk will fail at the same stress level irrespective of being subjected to stress cycles or not. If we assume that the chalk skeleton contains grain contacts like sketched in Figure 10, some of the contacts may include cement bonds while others may be purely frictional. The nonelastic deformation may then be due to shear movement at the frictional contacts, while failure starts when the more solid cement bonds begin to yield. However, the variation in $E$-modulus is not only due to the variation in nonelastic deformation. Also the stabilized moduli observed after several loading-unloading cycles, reflect a water weakening effect, which could be attributed to some stretching of the bonds.

\section{CONCLUSION}

So far, there are no inconsistencies between the model and the observations reported. But the hypothesis needs to be tested against a greater set of experimental results and observations in order to see if the idea of introducing repulsive forces reflects a main element in the mechanism behind chalk-water interactions.

In discussing water effects on reservoir chalks, focus should be on the properties of the chalk surfaces. Coating by organic films or other adsorbed layers may greatly affect the chalk-water interactions. The key parameter would probably be the wettability of the chalk.

\section{REFERENCES}

1 Kennedy, W.J. (1985) Sedimentology of the Late Cretaceous and Early Paleocene Chalk Group, North Sea Central Graben. Proc. North Sea Chalk Symposium, Book I, Stavanger, Norway, May 1985.

2 Baldwin, B.A. (1985) Characterization of Ekofisk Chalk Reservoir Surfaces. Proc. North Sea Chalk Symposium, Book III, Stavanger, Norway, May 1985.

3 Ruistuen, H. (1977) An Experimental and Numerical Study of Mechanical Behaviour of Weakly Cemented Reservoir Sandstones through Development of a Micromechanical Model. Thesis, Norwegian University of Science and Technology (NTNU), Trondheim.

4 Andersen, M.A., Foeged, N. and Pedersen, H.F. (1992) The Link between Waterflood-Induced Compaction and RateSensitive Behavior in a Weak North Sea Chalk. Proc. Fourth North Sea Chalk Symposium, Deauville, France, September 1992.

5 Monjoie, A., Schroeder, C., Prignon, Yernaux and da Silva, F. (1990) Establishment of Constitutive Laws of Chalk and Long Term Tests. Proc. Third North Sea Chalk Symposium, Copenhagen, Denmark, June 1990. 
6 Monjoie, A. and Schroeder, C. (1989) Caractéristiques mécaniques de craies du Crétacé supérieur. Journée craie, University of Lille, France.

7 Risnes, R., Garpestad, O.J., Gilje, M., Oland, L.T., Ovesen, M. and Vargervik, E. (1998) Strain Hardening and Extensional Failure in High Porosity Chalk. Proc. Eurock'98, Trondheim, Norway, July 1998.

8 Risnes, R., Gjesdal, S.A., Landaas, T.L. and Madland, I. (1994) Changes in Mechanical Properties of Chalk Caused by Deformation and by Pore Pressure. Proc. Eurock'94, Balkema, Rotterdam.

9 Delage, P., Schroeder, C. and Cui, Y.J. (1996) Subsidence and Capillary Effects in Chalk. Proc. Eurock'96, Balkema, Rotterdam.

10 Risnes, R., Kristensen, C.N. and Andersen, M.A. (1996) Triaxial Tests on High Porosity Chalk with Different Saturating Fluids. Proc. Fifth North Sea Chalk Symposium, Reims, France, October 1996.

11 Narvesen, T.R. (1997) Experiments with Miscible Exchange of Saturating Fluids in High Porosity Chalk. Thesis, Stavanger College, Stavanger, Norway, Spring 1997.

12 Risnes, R., Korsnes, R.I. and Vatne, T.A. (1999) Tensional Strength of Soft Chalks in Direct and Brazilian Tests. Proc. Ninth International Congress on Rock Mechanics, Paris, France, August 1999.
13 Murphy, W.F., Winkler, K.W. and Kleinberg, R.L. (1986) Acoustic Relaxation in Sedimentary Rocks: Dependence on Grain Contacts and Fluid Saturation. Geophysics, 51, 757766.

14 Hadizadeh, J. and Law, R.D. Water-Weakening and Quartzite Deformed at Various Stress and Strain Rates. Int. J. of Rock Mech., Min. Sci.\& Geomech. Abstr., 28, 5, 431-439.

15 Flaageng, O. and Risnes, R. (1999) Chalk-Fluid Interactions Measured by the Zeta Potential in Water/Methanol Mixtures. Proc. Second Euroconference on Rock Physics and Rock Mechanics, Edimburgh, Scotland, 14-18 November 1999.

16 Johnson, K.L., Kendall, K. and Roberts, A.D. (1971) Surface Energy and the Contact of Elastic Solids. Proc. R. Soc. Lond., 324, 301-313.

17 Paffenholz, J. and Burkhardt, H. (1989) Absorbtion and Modulus Measurements in the Seismic Frequency and Strain Range on Partially Saturated Sedimentary Rocks. Journal of Geophysical Research, 94, B7, 9493-9507, July 1989.

18 Nygaard, V. (1999) Chalk Behaviour in the "Elastic" Range. Effect of Fluids, Loading Rate and Loading-Unloading Sequences. Thesis, Stavanger College, Stavanger, Norway, Spring 1999. 